\title{
The Role of Metonymy in Advertisements
}

\author{
Chunling Liu, Jianwen Liu \\ School of Foreign Languages, Wuhan Polytechnic University, Wuhan, 430024, China
}

\begin{abstract}
Keywords: metonymy; advertisement; ICM;
Abstract. Nowadays, advertisement has undoubtedly been pervasive in our daily life. With the development of modern advertising, metonymy is heavily used in advertising creativity. As a rhetorical device, metonymy makes the advertisement more vivid through words. The theory of metonymy has been exited for years. The function of advertisement is to attract the customers and market the products. The simple word is difficult in moving the customers and making a good impression on customers. While it can enhance the promotional effect by using metonymy in advertisement. The two common ICM used in advertisement are Whole ICM and its parts and parts of an ICM. That category can be divided into more means, such as Things-and-part ICM,Category-and-Property ICM, Constitution ICM. In this paper, I will analyze the application of metonymy in advertisement and provide theoretical support for advertising production.
\end{abstract}

\section{Introduction}

Since the 1980s, the attention from cognitive filed initiated a new look on metonymy research. At the beginning, Lakoff and Johnson in their book Metaphor We Live By just mention metonymy when discussed metaphor. They did not pay more attention to metonymy. But from 1990s, Goosens(1990), Croft(1993) and Dirven(1993) began to focus on metonymy. In 1999, Panther \& Radden compiled the book Metonymy in Language and Thought which arose high attention on the research of metonymy. Then Radden \& Kövecses defined metonymy as a cognitive operational process which occurs at the same cognitive model. It was accepted by most of the scholars. Besides, Dirven \& Poring in their collected papers Metaphor and Metonymy in Comparison and Contrast discussed the relation between metonymy and metaphor.Two new breakthroughs in the cognitive linguistics approach to metaphor and metonymy have been developed: one is the three-domain approach, which concentrates on the new blends that become possible after the integration or the blending of source and target domain elements; the other is the approach in terms of primary scenes and subscenes which often determine the way source and target domains interact.

\section{Analysis of application of metonymy in advertisement}

The features of adverting language. The word"advertising"originate from "advertere" which means that it is a way to attract people's attention on something. Speaking of advertising, it is not simple commercial language. It should conform to the principle of psychology and meet people's needs of emotion. It also shows great attraction and appeal in order to reach the purpose of persuasion. Therefore,the intrinsic quality of advertisement need advertisement be inflammatory. At the same time,advertisement is to promote the product in the way of paying. A person once said that every word in the copy must count. So the company should pay more attention on advertisement.

The 'KISS' principle in advertising. As a special language,advertising has its own features.In the area of creative advertising,there is a famous "KISS" principle--keep it simple and sweet. It is one of the most important principle in the writing of advertisement copy. With the fierce competition in the modern society, there follows overwhelming advertisements. It is important in advertising that the company should give a great impression within limited time and space. So the advertisement prefers short and simple sentences.For example, "A diamond lasts forever"This advertisement is a typical simple sentence.

It has high readability and can make audience clear at a glance. Simple sentence is easy to attract people's attention and make it easy to understand and remember. Besides, if the company needs to put 
the advertisement on TV, it can be too long and tedious. People always has little time on advertisement. So many advertisements try to be short and simple. In addition, elliptical sentences can always be found in advertising.For example in the advertisement of NEC company,"Empowered by innovation" It means to use innovation to propel the development of technology and company.Although the subject and other parts are elliptical,it highlight the connation and features of the company. In advertising,we need to keep it simple and sweet.

Vivid language and profound meaning in advertising. The purpose of advertising is to promote people's consumption. The language in advertisement should stir up consumer's association so as to consolidate the memory. Therefore, another feature of advertising is to touch consumer using sincerity and encourage people to have desire to buying goods. We can see vivid words in advertising, and it seems that we are affected by the advertisement. We can easily imagine some scene.In order to make advertising vivid, we can use rhetorical figures,such as antithesis,parody,simile. In the advertisement of Mitsubishi Motors Corporation,"Not all cars are created equal", this advertisement copy the sentence in

American's Declaration of Independence--All men are created equal. It can make people easy to remember and people will have a good impression on the quality of the car. "Give me Green World,or give me yesterday" is another advertising. When first hearing the advertising,we have a feeling of having meet before. Because the famous American politician Henry once said "give me liberty,or give me death". The form makes people's eye pop out,and its content is also novel,vivid. It implies a profound meaning that Green World can make women be young forever. So many people are likely to buy the goods.

Be humorous and innovative. Advertisement is a kind way of propagandizing filling with art content. It is a function of advertising to make people enjoy the advertisement. Many advertisements are boring and tedious, people have no memory about those advertisements. If the company want to attract people's eyes at first glance,they would better use suitable,such as using alliteration, parallelism. These form of expression can be easily remember and keep in one's mind for a long time. In addition, the advertisements should be humorous and full of innovation. In general, something humorous can quickly catch people's eyes. For example, "Export fair set for foreign-funded firms" It is a advertisement for export products expo of foreign-owned enterprise. It is vivid and novel.The words "fair,for,foreign,funded,firms", are alliteration. It seems that they are welcoming the foreign-funded enterprise. An advertisement for a outdoor bathing place said "More sun and air for you son and heir sun and son, air and heir are phonogram, the producer takes advantage of these two phonogram. It is not only sweet-sounding but also interesting. Its novelty can attract many parents to go to the outdoor bathing place with their children. Creative advertisements can not be without innovation. We can create great advertisements with lot of methods. Metonymy is one of methods. By using metonymy in advertisement,we can improve the quality of advertisement and make the advertisement more attracting and impressive.

The role of metonymy in advertising. Nowadays, a large number of advertisements appear in $\mathrm{TV}$, billboard everyday. Many are attracting and impressive. The producer will try his best to use many methods to create amazing advertisement. Among many methods, metonymy is one common method. According a study on advertisement, the advertisement using metonymy account for 58 percent. We can see from that data that metonymy is very important in advertising. According to cognitive views of metonymy, metonymy is a conceptual tool that operate within "idealized cognitive models "(Lakoff 1987). Among the most ICMs, what is common used are Whole for part ICMs and Part for part ICMs. The Whole for part ICMs mainly include scale ICM, constitution ICM, Category-and-member ICM. The Part for part ICMs mainly include perception ICM, production ICM, control ICM,containment ICM. In the following,I will analyze the application of metonymy in advertisement with examples.

Whole for part ICMs. It is one of the most important part of metonymy. It also include many other ICMs. Thing and their parts is a typical relationship in a whole and a part ICM."Thing"is defined as a whole with well-delineated boundaries and internally composed of various parts. In the 
Thing-and-Part ICM, it can be divided into two parts:part of a thing for the whole thing, whole thing for the part of a thing. I would use some examples to illustrate as following:

(1) Our wheels are always turning. It is an advertisement of ISUZU cars.In this advertisement, it applies part of a thing for the whole thing."Wheel"is the vehicle, it replaces the ISUZU cars. It means that ISUZU cars are always improving and the cars are of high quality.

(2) Wash the big city out of hair. It is an advertisement of shampoo.It is an example of Whole thing for a part. In the advertisement, " the big city"refers to the dirt of the hair. The big city is often related to a lot of moving cars,motors.so we can take it as the dirt of the big city. It give us a impression that the shampoo is practical.

Another common used ICM is constitution ICM. It involves matter ,material or substances which are seen as constituting a thing. It can be divided in two parts:Object for material constituting and Material constituting an object for the object. In this ICM,substance things are characterized as being unbounded and uncountable. They do not have parts but are constituted by their substance.

Tide's in ,dirt's out

It is an advertisement of Tide washing powder. In this advertisement, Tide is the object,it replace the constitution of washing powder. Besides, it uses rhetorical figure-alliteration and can be remembered easily.

(4)World in hand, soul in Cyber. It is the advertisement of Microsoft company. In this advertisement,"soul"is refers to mind. It also use antithesis and highlights the importance of cyber.

Part for part ICMs. There is another type of ICM--Part for part ICM. It is mainly applies to the relationship between parts. Metonymy also arises when a relation is construed as a thing or a thing is construed as a relation. So the Part for part ICMs consist of the Action ICM, the Perception ICM, the Causation ICM, the Production ICM, the Control ICM, the Possession ICM, the Containment ICM, the Location ICM, the Sign and Reference ICM and the Modification ICM. In this paper,I just introduce the two common used ICMs, the production ICM, the causation ICM.

The causation ICM is often used in advertisement. Cause and effect are so closely interdependent that one of them tends to imply the other. This ICM can be divided into two parts:cause for effect and effect for cause. Let us see some examples.

Ask for more

It is an advertisement for Pepsi fashion shoes. In this advertisement, the cause is "ask for more",it refers to the effect that the shoes is popular and many people want to buy the shoes.

(6) We are driving excitement.

It is the advertisement of PONTIAC. The result is that we are driving excitement. It refers to the cause that driving the car makes us excited. When seeing the advertisement, consumer can feel that the car can make us excited.

Another ICM is production ICM. It involves actions in which one of the participants is a product created by the action. The production of objects seems to be a particularly salient type of causal action. This ICM also includes two kinds of metonymic models--producer for product and instrument for product.

(7) Fresh-up with Seven-up

It is the advertisement of Seven-up. The producer is Seven-up. It is refers to the drinks produced by the Seven-up. It means that you can be energetic by drinking Seven-up.

Ford has a better idea:

"Ford" is metonymically understood as the car produced by the Ford Company.

The function of metonymy in advertising. From the examples above,we can find that it is important in advertisement to use metonymy. It can improve the quality of advertisements. The company creating advertisement is to improve the sales of their products. So the advertisements should be interesting. Thus great advertisement can be without metonymy. There are a lot of functions of metonymy in advertisement. First of all, it can arouse consumer's perception. If the advertisement is very attracting and interesting,people will be curious about the product . They will try to find the information of the product. So sales of the product can be improved. Secondly, the use 
of metonymy in advertisement can help consumers build a more vivid image. For example, "Pity the pickpocket"is an advertisement for a clothing. "pickpocket" refers to the the thief. Why should we pity the thief? It is because the design of safe pocket can protect us being stealed. By seeing this advertisement,we can imagine the scene. It can give a deep impression on the consumer. "Light as a breeze ,soft as a cloud" is an advertisement for a clothing. It highlights the comfortable sensation of the shell fabric and build a vivid image for us. It seems that it is really can be so comfortable. There are other functions of metonymy. In the future,metonymy can be more largely used in advertisement.

\section{Conclusion}

In this article, we mainly introduce the application of metonymy in advertisement. At first, we introduce the domestic and foreign situation of the research. In order to know more about the metonymy, we talk about the three different views on metonymy and introduce the research on the definition of metonymy, the essence of metonymy, the classification of metonymy. Then, we illustrate the features of advertisement. As a special way of promotion, the advertising language should be simple, vivid and humorous. There is also a "KISS" principle in advertising creation. The metonymy can be divided in two parts. We elaborate the application of metonymy in advertisement and take many examples in order to make it easy to understand. Through these examples, we know that it makes the advertisement more interesting and vivid by using metonymy. It not only can arouse consumer's perception but also help consumer build a vivid image. Through writing this article, we want to provide theoretical support for the creation of advertisement and improve the quality of advertisements.

\section{Acknowledgments}

The research was supported by Wuhan Polytechnic University under Grant No. 2016y13.

\section{References}

[1] Bell, A. The Language of News Media. London: Wiley Blackwell,1991.

[2] Cook, G. The Discourse of Advertising. London: Routledge,1992.

[3] Fass, D. Processing Metaphor and Metonymy. London: Ablex,1997.

[4] Jakobson, Two Aspects of Language and Two Types of Aphasic Disturbances. Fundamentals of Language. The Hague: Mouton, pp. 101-118, 1956.

[5] Kress,G. Education Readers: Language in advertising. Propaganda, Persuasion Polemic. London: Arnold, pp. 87-91, 1987.

[6] Lakoff, G and Johnson, M. Metaphors We Live By. Chicago: The University of Chicago, 1980.

[7] Lakoff, G. Women, Fire and Dangerous Things: What categories reveal about the Mind. Chicago: The University of Chicago, 1987.

[8] Lakoff, G. Language and Woman's Place. New York: Harper and Row, 1957.

[9] Paula Pérez-Sobrino. Multimodal Metaphor and Metonymy in Advertising: A Corpus-Based Account. Metaphor and Symbol, 31(2), pp. 73-90, 2016. 